\title{
Communication
}

\section{Growth of Crossed ZnO Nanorod Networks Induced by Polar Substrate Surface}

\author{
J. H. He, C. H. Ho, C. W. Wang, Y. Ding, L. J. Chen, and Zhong L. Wang
}

Cryst. Growth Des., 2009, 9 (1), 17-19 • DOI: 10.1021/cg800530n • Publication Date (Web): 18 November 2008

Downloaded from http://pubs.acs.org on February 5, 2009

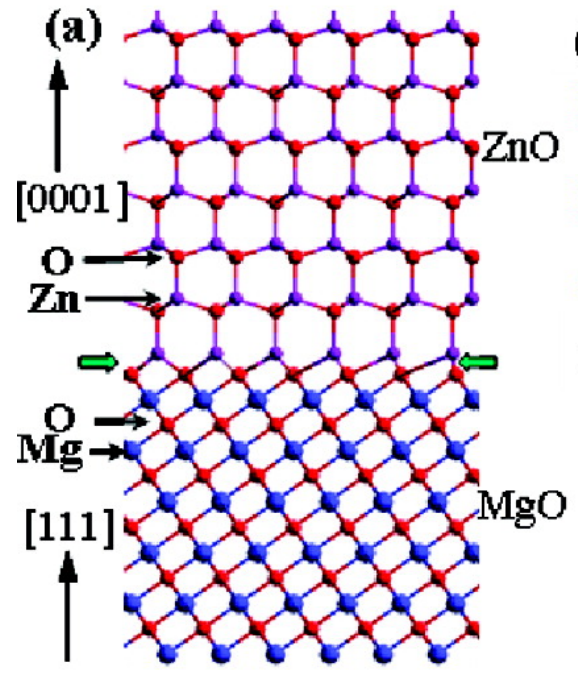

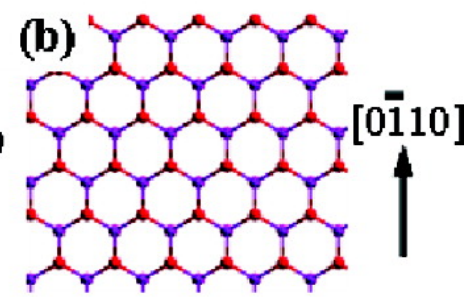

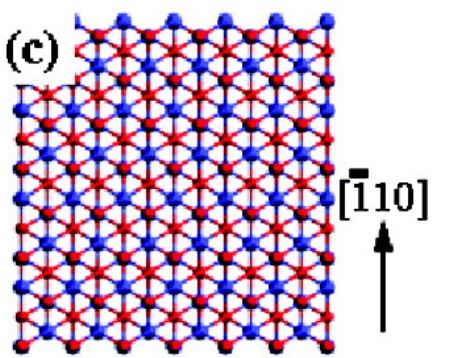

\section{More About This Article}

Additional resources and features associated with this article are available within the HTML version:

- Supporting Information

- $\quad$ Access to high resolution figures

- $\quad$ Links to articles and content related to this article

- Copyright permission to reproduce figures and/or text from this article

\section{View the Full Text HTML}




\title{
Growth of Crossed ZnO Nanorod Networks Induced by Polar Substrate Surface
}

\author{
J. H. He, ${ }^{* \dagger}$ C. H. Ho, ${ }^{\dagger}$ C. W. Wang, ${ }^{\dagger}$ Y. Ding, ${ }^{\S}$ L. J. Chen, ${ }^{\ddagger}$ and Zhong L. Wang ${ }^{\S}$ \\ Institute of Photonics and Optoelectronics and Department of Electrical Engineering, National Taiwan \\ University, Taipei, 106 Taiwan, Department of Materials Science and Engineering, National Tsing \\ Hua University, Hsinchu, 300 Taiwan, and School of Materials Science and Engineering, Georgia \\ Institute of Technology, Atlanta, Georgia 30332-0245
}

Received May 19, 2008; Revised Manuscript Received November 5, 2008

\begin{abstract}
We show that by controlling the growth conditions, the crossed networks of $\mathrm{ZnO}$ nanorods were grown on an $\mathrm{MgO}$ (001) substrate. The [0001] $\mathrm{ZnO}$ nanorods grow along the $\langle 111\rangle$ directions of $\mathrm{MgO}$ substrate and form aligned arrays. This growth is a result of polar surface induced growth from both the $\mathrm{MgO}\{111\}$ and $\mathrm{ZnO} \pm(0001)$. The crossed $\mathrm{ZnO}$ nanorod networks are a potential candidate for field emission, optoelectronics, ultrasensitive sensing, catalysts and filtering.
\end{abstract}

Wurtzite-structured $\mathrm{ZnO}$ is of great importance because of its versatile applications in optoelectronics, photovoltaics, and sensors. ${ }^{1}$ Quasi-one-dimensional nanostructures of $\mathrm{ZnO}$, such as nanowires, nanobelts, and nanotubes, have been a relevant research topic in nanotechnology for their unique properties and potential applications. $^{2-7}$ As a wurtzite-structured oxide, zinc oxide is of three types and a total of 13 fastest growth directions: [0001], $<01 \overline{10}>$, and $\langle 2 \overline{1} 10>$. Together with a pair of polar-surfaces such as $\{0001\}$, a unique group of novel nanostructures have been grown, such as asymmetric nanocantilever arrays, ${ }^{8}$ nanojunction-arrays, ${ }^{9}$ piezoelectric nanobelts, ${ }^{10}$ nanosprings, ${ }^{11}$ and nanorings. ${ }^{12}$

Ordered nanorod networks are potential building blocks for memory and logic devices as well as interconnects, with the possibility of playing a key role in the future nanoscale electronics and optoelectronics. ${ }^{13-27}$ So far, a number of network structures have been grown for several different materials, including carbon nanotubes (CNTs), InP, GaP, Se, and Si. ${ }^{15,18-22}$ Because of the extremely small size of nanorods, organizing nanorods into ordered patterns by direct manipulation is slow and difficult. To solve this problem, researchers have demonstrated a few techniques based on an assembly method under the control of external forces. Chemical vapor deposition on patterned catalyst produced interconnected networks of CNTs. ${ }^{18}$ By employing microfluidics to align the nanorods within a lithographically defined channel, InP and $\mathrm{GaP}$ nanowires have been organized into cross arrays. ${ }^{19}$ Crossed networks of CNTs have been grown using electric-field-assisted deposition and orientation. ${ }^{20}$ Template-directed CNT network formation using self-organized Si nanocrystals, ${ }^{21}$ three-dimensional Se nanowire networks, ${ }^{14}$ and $\mathrm{Si}$ nanowire networks controlled by the orientation of the substrate ${ }^{22}$ have been demonstrated. So far, several types of 3D ZnO nanostructures have been synthesized. ${ }^{26,27}$ For example, $\mathrm{ZnO}$ nanowires at the junctions of $\mathrm{ZnO}$ nanowalls have been synthesize. It demonstrated that $1 \mathrm{D}$ and $2 \mathrm{D}$ nanostructures with with high crystallinity can be epitaxially and vertically grown into 3D architectures on both conducting and insulating single-crystalline substrates. ${ }^{26}$ Moreover, $\mathrm{ZnO}$ nanowire arrays can be obtained with each nanowire forming an angle $\sim 30^{\circ}$ with the $m$-sapphire substrate normal by taking advantage of the good epitaxial interface between the (0001) plane of $\mathrm{ZnO}$ and the $(11 \overline{2} 0)$ plane of the sapphire. ${ }^{27}$ Because of the high surface/volume ratio, 3D oxide nanorod networks have been demonstrated as a highsurface-area material for building ultrasensitive and highly selective gas sensors. ${ }^{23}$

* To whom correspondence should be addressed. E-mail: jhhe@ cc.ee.ntu.edu.tw.

† National Taiwan University.

* National Tsing Hua University.

$\S$ Georgia Institute of Technology.
In this communication, we report the growth of crossed nanorod networks of $\mathrm{ZnO}$ on $\mathrm{MgO}$. The structure of the crossed $\mathrm{ZnO}$ networks is characterized, and its formation process is explained on the basis of polar surfaces for both the substrate and the $\mathrm{ZnO}$. The photoluminescence (PL) spectrum of $\mathrm{ZnO}$ nanowrie networks exhibits a strong emission peak at $386 \mathrm{~nm}$. The $3 \mathrm{D}$ crossed $\mathrm{ZnO}$ network reported here could be important for applications in the transistor, optoelectronics, field emission, filtering, catalysis, and gas sensing.

Experimental Section. In the vapor-liquid-solid (VLS) growth, a $2 \mathrm{~nm}$ thick Au thin film was deposited onto the (001) $\mathrm{MgO}$ substrates at room temperature in an electron beam evaporation system at a pressure of $\sim 5 \times 10^{-6}$ Torr. Upon heating, the $\mathrm{Au}$ nanoparticles served as the catalyst for the VLS growth. The experimental apparatus includes a horizontal tube furnace, a rotary pump system, and a gas supply system. A mixture of commercial $\mathrm{ZnO}$ and graphite powders in a 4:1 $\mathrm{Zn}: \mathrm{C}$ ratio was placed in an alumina boat, which was heated to a peak temperature of $1100^{\circ} \mathrm{C}$. The $\mathrm{MgO}$ substrate was placed at a temperature zone of $\sim 800^{\circ} \mathrm{C}$ for collecting $\mathrm{ZnO}$ nanostructures. After the tube had been evacuated to a pressure of $1 \times 10^{-3}$ Torr, the samples were heated to $1100{ }^{\circ} \mathrm{C}$ at a rate of $5{ }^{\circ} \mathrm{C} / \mathrm{min}$ and held at $1100{ }^{\circ} \mathrm{C}$ for $30-120$ min with a mixture of $25 \mathrm{sccm}$ Ar and $5 \mathrm{sccm} \mathrm{O}_{2}$ flowing through the tube.

After the growth process, the resulting product was collected for phase identification using grazing incidence X-ray diffractometry (XRD) with a fixed incident angle of $0.5^{\circ}$. The substrate-bound nanorods were mechanically scrapped and sonicated in ethanol and deposited on carbon-coated copper grids for transmission electron microscope (TEM) characterization. Morphological studies of grown $\mathrm{ZnO}$ nanostructures have been performed with a JEOL 2010 TEM operating at $200 \mathrm{kV}$ and a JEOL JSM-6500 field emission scanning electron microscopy (SEM). The PL properties of synthesized nanorods were studied at room temperature using a $\mathrm{He}-\mathrm{Cd}$ laser with a wavelength of $325 \mathrm{~nm}$ as the excitation source.

Results and Discussion. For the samples cooled down to room temperature, the structure of the as-grown nanorods was determined by XRD. As shown in Figure 1, all of the diffraction peaks can be ascribed to the hexagonal-structured $\mathrm{ZnO}$ with the lattice constants of $a=0.325 \mathrm{~nm}$ and $c=0.52 \mathrm{~nm}$, consistent with the standard data file (ICDD-PDF36-1451). No characteristic peaks from other phases were observed.

For the samples heated to $1100{ }^{\circ} \mathrm{C}$ and held at $1100{ }^{\circ} \mathrm{C}$ for 30 min, self-oriented $\mathrm{ZnO}$ nanowires were grown on the $\mathrm{Au}$-deposited (001) $\mathrm{MgO}$ substrate, as shown in Figure 2. Figures 2a is a top view $\mathrm{SEM}$ image of the $\mathrm{ZnO}$ arrays on the $\mathrm{MgO}$ substrates. Figure $2 \mathrm{~b}$ shows a cross-sectional SEM image of the sample with the viewing 


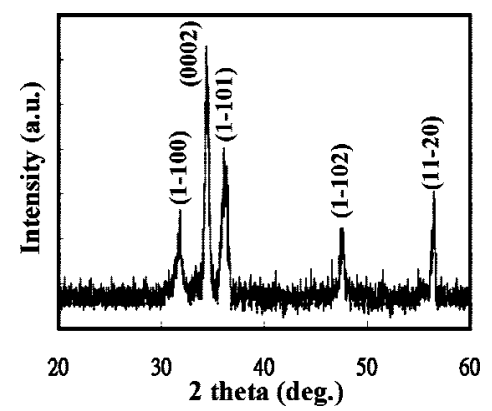

Figure 1. XRD pattern recorded from the as-synthsized products.
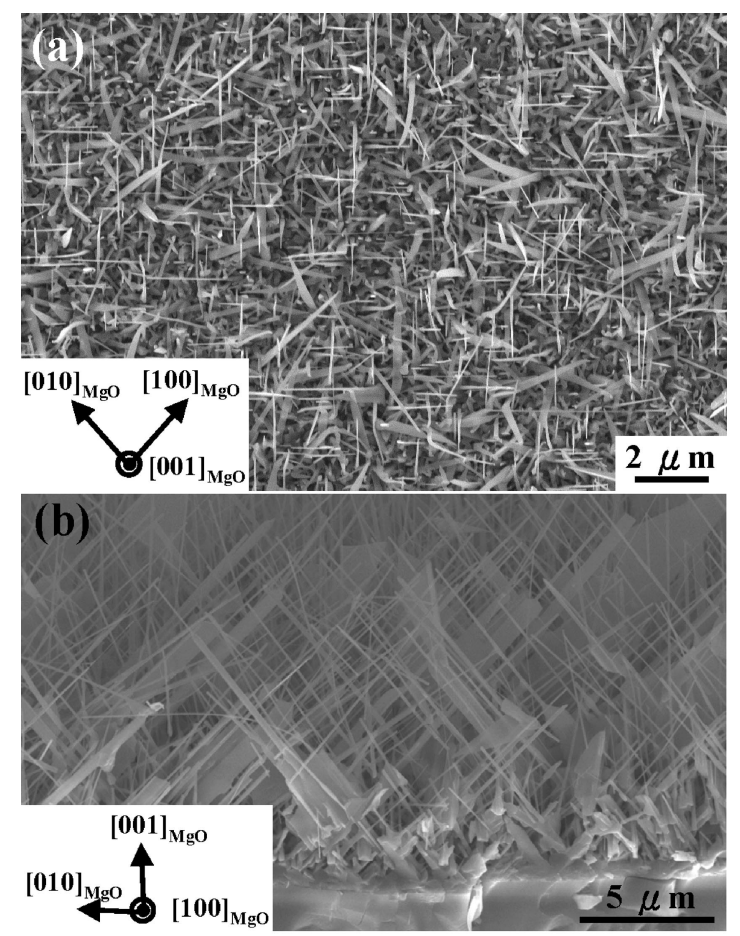

(c)

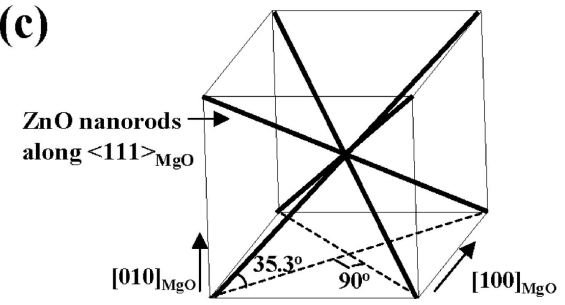

Figure 2. (a) Plan-view SEM image with the viewing direction $[001]_{\mathrm{MgO}}$ and (b) cross-sectional SEM image with the viewing direction of $[100]_{\mathrm{MgO}}$ of the $\mathrm{ZnO}$ arrays grown on an $(001) \mathrm{MgO}$ substrate and (c) schematic illustration of the four $\langle 111\rangle_{\mathrm{MgO}}$ growth directions of the $\mathrm{ZnO}$ nanowires on an (001) $\mathrm{MgO}$ substrate. Dashed lines represent the projections of the $\mathrm{ZnO}$ nanorods, which are perpendicular to each other.

direction of the $[100]_{\mathrm{MgO}}$. The relative crystal orientations are shown in the insets of $\mathrm{a}$ and $\mathrm{b}$ in in the Figure 2. It is clear that these $\mathrm{ZnO}$ nanorods formed crossed networks. In addition, beltlike $\mathrm{ZnO}$ nanostructures were also formed. From the information provided by images $\mathrm{a}$ and $\mathrm{b}$ in Figure 2, the $\mathrm{ZnO}$ nanorods grow along the $\langle 111\rangle$ direction of the $\mathrm{MgO}$ substrate, as shown schematically in Figure 2c. In the present study, there are four directions of the growth for $\mathrm{ZnO}$ nanowire on the $\mathrm{MgO}$ substrates, which is a result of polar surface induced growth. In contrast, crossed $\mathrm{ZnO}$ nanowire networks on $m$-sapphire substrates were obtained by taking

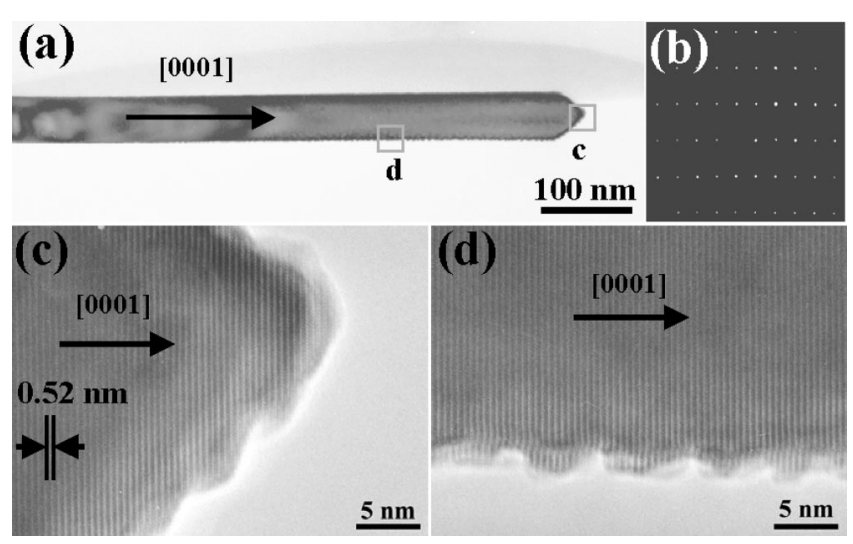

Figure 3. (a) TEM image of a single $\mathrm{ZnO}$ nanowire, (b) corresponding selected area diffraction pattern, and (c, d) HRTEM images from the outlined areas in (a).

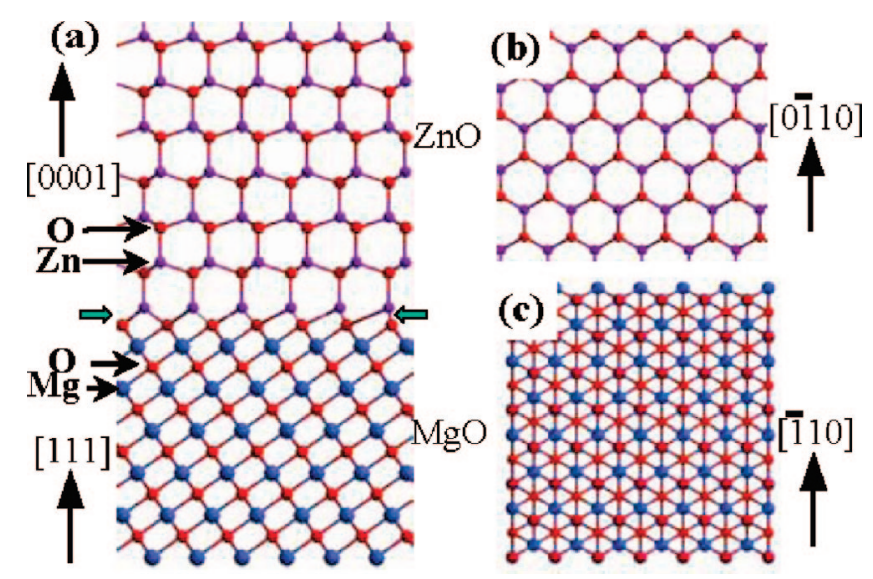

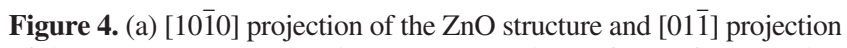
of the $\mathrm{MgO}$ structure, showing \pm (0001) polar surfaces of $\mathrm{ZnO}$ and \pm (111) polar surfaces of $\mathrm{MgO}$, respectively. (b) [0001] projection of $\mathrm{ZnO}$ structure and (c) [111] projection of $\mathrm{MgO}$ structure.

advantage of the good epitaxial interface between the (0001) plane of $\mathrm{ZnO}$ and the $(11 \overline{2} 0)$ plane of the sapphire. ${ }^{27}$

TEM has been performed to further characterize the $\mathrm{ZnO}$ nanostructures. Figure 3 a shows a typical TEM image of the single $\mathrm{ZnO}$ nanorod with a sharp tip. The diameter is about $50 \mathrm{~nm}$. The corresponding selected area electron diffraction, as shown in Figure 3 (b), confirms that the phase of nanorods is hexagonal wurtzitestructured $\mathrm{ZnO}$. Images $\mathrm{c}$ and $\mathrm{d}$ in Figure 3 are high-resolution TEM (HRTEM) images from the outlined region indicated in Figure $3 a$. Images $\mathrm{c}$ and $\mathrm{d}$ in Figure 3 depicts that $\mathrm{ZnO}$ nanorods are singlecrystalline and free of defects. The growth direction of $\mathrm{ZnO}$ nanorod was determined to be $[0001]_{\mathrm{ZnO}}$.

To understand the growth orientation of the [0001] $\mathrm{ZnO}$ nanorods on the (001) $\mathrm{MgO}$ substrate, we start from the structure of $\mathrm{ZnO}$. $\mathrm{ZnO}$ has the hexagonal structure with $a=0.325$ and $c$ $=0.52 \mathrm{~nm}$. $\mathrm{ZnO}$ can be simply viewed as composed of alternative layered $\mathrm{Zn}^{2+}$ and $\mathrm{O}^{2-}$ ions planes parallel to the basal plane. The (0001) and (0001) surfaces of $\mathrm{ZnO}$ are terminated with $\mathrm{Zn}^{2+}$ and $\mathrm{O}^{2-}$ ions, respectively, which are known as the polar surfaces. $\mathrm{MgO}$ has the $\mathrm{NaCl}$ cubic structure with lattice parameter of $a=0.421 \mathrm{~nm}$. The $\mathrm{Mg}^{2+}$ and $\mathrm{O}^{2-}$ ions are distributed alternatively in parallel to the $\{111\}$ plane, thus, the $\{111\}$ polar surface can be terminated either with $\mathrm{Mg}^{2+}$ or $\mathrm{O}^{2-}$. The structure model of growth of [0001] $\mathrm{ZnO}$ nanorods along the $\langle 111\rangle_{\mathrm{MgO}}$ direction is shown in Figure $4 \mathrm{a}$. The structure models of the $\mathrm{ZnO}$ along [0001] direction and $\mathrm{MgO}$ along [111] direction are illustrated in images $b$ and $c$ in Figure 4. The (001) surface of $\mathrm{MgO}$, however, is a nonpolar surface, thus a direct 


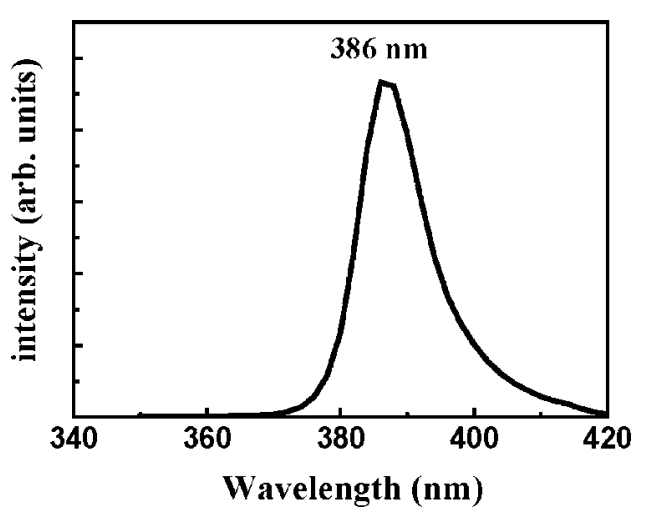

Figure 5. Photoluminescence spectrum of $2 \mathrm{D}$ rectangular $\mathrm{ZnO}$ nanowire network.

stacking of [0001] $\mathrm{ZnO}$ nanorod along [001 $]_{\mathrm{MgO}}$ is restricted by the crystal symmetry, lattice mismatch as well as the surface charge. On the other hand, the $(001)_{\mathrm{MgO}}$ surface may be rough as a result of polishing, and it can exhibit tiny $\{111\}$ type facets. Because of the polar charges on both $\mathrm{MgO}\{111\}$ and $\mathrm{ZnO} \pm$ (0001), a direct facing of $\mathrm{ZnO}(000 \overline{1})-\mathrm{O}^{2-}$ onto $\mathrm{MgO}$ (111) $-\mathrm{Mg}^{2+}$ would be a natural choice from the surface charge point of view. A previous work on the growth of $\mathrm{ZnO}$ thin films on sapphire substrate with $\mathrm{MgO}$ buffer layer also demonstrated the mechanism of polar-surface-induced growth. ${ }^{28}$ Thus, the $\mathrm{ZnO}$ nanorod will grow along [0001] with the Zn-terminated surface in front. From our previous study, ${ }^{7} \mathrm{Zn}$ terminated (0001) is selfcatalytically active for nanorod growth, resulting in the growth of $\mathrm{ZnO}$ nanorods.

From the symmetry point of view, both $(0001)_{\mathrm{ZnO}}$ and (111) $\mathrm{MgO}$ planes have 6-fold symmetry. The lattice mismatch between the two prominent planes $\{110\}_{\mathrm{MgO}}$ to $\{2 \overline{1} \overline{1} 0\}_{\mathrm{ZnO}}$ is as high as $10.4 \%$. This lattice mismatch is large enough to prevent the growth of largesize epitaxial films, but facilitate the formation of small size nuclei of $\mathrm{ZnO}$ leading eventually to the growth of nanorods.

Figure 5 shows a room-temperature PL spectrum of the crossed $\mathrm{ZnO}$ nanorod networks. There is a strong emission peak at 383 $\mathrm{nm}$, corresponding to the near band edge emission of $\mathrm{ZnO}$ material. Encouraged by the recent demonstration of ultrasensitive and highly selective gas sensors using three-dimensional tungsten oxide nanowire networks, ${ }^{23}$ a study on the gas sensing capability may yield very positive results. Furthermore, field emission, optoelectronic, and filtering performances of $3 \mathrm{D}$ crossed $\mathrm{ZnO}$ nanorod network should be explored since it appears as a promising material for such applications because of its unique nanostructure.

Conclusion. In summary, we show that by controlling the growth conditions, the crossed networks of $\mathrm{ZnO}$ nanorods were grown on an $\mathrm{MgO}$ (001) substrate. The [0001] $\mathrm{ZnO}$ nanorods grow along $\langle 111\rangle$ directions of $\mathrm{MgO}$ and form ordered arrys. This growth is a result of polar surface induced growth from both the $\mathrm{MgO}$ $\{111\}$ and $\mathrm{ZnO} \pm(0001)$.
Acknowledgment. The research was supported by the National Science Council, Grants NSC 96-2112-M-002-038-MY3 and NSC 96-2622-M-002-002-CC3, and Aim for Top University Project from the Ministry of Education.

\section{References}

(1) Heo, Y. W.; Norton, D. P.; Tien, L. C.; Kwon, Y.; Kang, B. S.; Ren, F.; Pearton, S. J.; LaRoche, J. R. Mater. Sci. Eng., R 2004, 47, 1.

(2) He, H.; Lao, C. S.; Chen, L. J.; Davidovic, D.; Wang, Z. L. J. Am. Chem. Soc. 2005, 127, 16376.

(3) Comini, E.; Faglia, G.; Sberveglieri, G.; Pan, Z. W.; Wang, Z. L. Appl. Phys. Lett. 2002, 81, 1869.

(4) He, H.; Hsin, C. L.; Liu, J.; Chen, L. J.; Wang, Z. L. Adv. Mater. 2007, 19, 781 .

(5) He, J. H.; Lin, Y. H.; McConney, M. E.; Tsukruk, V. V.; Wang, Z. L.; Bao, G. J. Appl. Phys. 2007, 102, 084303.

(6) Yu, C.; Hao, Q.; Saha, S.; Shi, L.; Kong, X. Y.; Wang, Z. L. Appl. Phys. Lett. 2005, 86, 063101.

(7) He, J. H.; Ho, S. T.; Wu, T. B.; Chen, L. J.; Wang, Z. L. Chem. Phys. Lett. 2007, 435, 119.

(8) Wang, Z. L.; Kong, X. Y.; Zuo, J. M. Phys. Rev. Lett. 2003, 91, 185502.

(9) Lao, J. Y.; Wen, J. G.; Ren, Z. F. Nano Lett. 2002, 2, 1287.

(10) Kong, X. Y.; Wang, Z. L. Nano Lett. 2003, 3, 1625.

(11) Kong, X. Y.; Wang, Z. L. Appl. Phys. Lett. 2004, 84, 975.

(12) Kong, X. Y.; Ding, Y.; Yang, R. S.; Wang, Z. L. Science 2004, 303, 1348.

(13) He, J. H.; Hsu, J. H.; Wang, C. W.; Lin, H. N.; Chen, L. J.; Wang, Z. L. J. Phys. Chem. B. 2006, 110, 50.

(14) Cao, X. B.; Xie, Y.; Li, L. Y. Adv. Mater. 2003, 15, 1914.

(15) Li, Q. C.; Kumar, V.; Li, Y.; Zhang, H. T.; Marks, T. J.; Chang, R. P. H. Chem. Mater. 2005, 17, 1001.

(16) Ho, S. T.; Chen, K. C.; Chen, H. A.; Lin, H. Y.; Cheng, C. Y.; Lin, H. N. Chem. Mater. 2007, 19, 4083.

(17) He, J. H.; Wu, T. H.; Hsin, C. L.; Li, K. M.; Chen, L. J.; Chueh, Y. L.; Chou, L. J.; Wang, Z. L. Small 2006, 2, 116.

(18) Cassell, A. M.; McCool, G. C.; Ng, H. T.; Koehne, J. E.; Chen, B.; Li, J.; Han, J.; Meyyappan, M. Appl. Phys. Lett. 2003, 82, 817.

(19) Huang, Y.; Duan, X. F.; Wei, Q. Q.; Lieber, C. M. Science 2001, 291,630

(20) Yang, B.; Marcus, M. S.; Keppel, D. G.; Zhang, P. P.; Li, Z. W.; Larson, B. J.; Savage, D. E.; Simmons, J. M.; Castellini, O. M.; Eriksson, M. A.; Lagally, M. G. Appl. Phys. Lett. 2005, 86, 263107.

(21) Diehl, M. R.; Yaliraki, S. N.; Beckman, R. A.; James, M. B.; Heath, R. Angew. Chem., Int. Ed. 2002, 41, 353.

(22) Ge, S. P.; Jiang, K. L.; Lu, X. X.; Chen, Y. F.; Wang, R. M.; Fan, S. S. Adv. Mater. 2005, 17, 56.

(23) Ponzoni, A.; Comini, E.; Sberveglieri, G.; Zhou, J.; Deng, S. Z.; Xu, N. S.; Ding, Y.; Wang, Z. L. Appl. Phys. Lett. 2006, 88, 20310.

(24) Wu, Y.; Xi, Z. H.; Zhang, G. M.; Zhang, J. L.; Guo, D. Z. Cryst. Growth Des. 2008, 8, 2646.

(25) Zhang, D. F.; Sun, L. D.; Zhang, J.; Yan, Z. G.; Yan, C. H. Cryst. Growth Des. 2008, 8, 3609.

(26) Ng, H. T.; Li, J.; Smith, M. K.; Nguyen, P.; Cassell, A.; Han, J.; Meyyappan, M. Science 2003, 300, 1249.

(27) Ng, H. T.; Chen, B.; Li, J.; Han, J. E.; Meyyappan, M.; Wu, J.; Li, S. X.; Haller, E. E. Appl. Phys. Lett. 2003, 82, 2023.

(28) Kato, H.; Miyamoto, K.; Sano, M.; Yao, T. Appl. Phys. Lett. 2004, $84,4562$.

CG800530N 